\title{
Tracing the oceanic Mo isotope variation through the Ediacaran- Cambrian transition
}

\author{
Yuntao Ye, Huajian Wang, Shuichang Zhang
}

Research Institute of Petroleum Exploration and

Development, Beijing, 100083, China

Correspounding author: yeyuntao@petrochina.com.cn

Paleontological and stratigraphic records reveal multipluses of biological novelty during the Ediacaran-Cambrian transition. This evolutionary event, representing one of the most significant changes in Earth history, is characterized by an abrupt diversification of animals, the first appearance of most extent phyla, and even the rise of Phanerozoic-style marine ecosystems. Based on research from South China, a broadly three-phase radiation is suggested. Although the distribution pattern can be some sort of different at different localities in the world, it reflects the essential feature of rapid innovation from $\sim 635$ to $\sim 520 \mathrm{Ma}$.

The geochemistry of Mo isotopes has attracted much attention in addressing the above questions. Applications of this tool rely on the different isotopic fractionations under different redox states. Current literature on Mo isotopes merely uses the highest $\delta^{98} \mathrm{Mo}$ of euxinic sediments to represent seawater $\delta^{98}$ Mo signal. However, processes such as non-steady-state Mo deposition or Rayleigh distillation have been shown to be capable of driving $\delta^{98}$ Mo larger than coeval seawater. These values, if considered as primary seawater $\delta^{98} \mathrm{Mo}$, may underestimate the true size of seafloor anoxia. Hence, a more comprehensive approach is needed to evaluate seawater $\delta^{98} \mathrm{Mo}$.

Based on the concept that modern open marine anoxic sites express a constant $0.7 \%$ fractionation between the seawater Mo source and authigenic sediments, we re-estimate the oceanic Mo isotope compostion by constraining an lower and an upper values. The inferred seawater $\delta^{98} \mathrm{Mo}$ of the Ediacaran upper Doushantuo Formation is $1.2-1.4 \%$ o $(\sim 560-$ $551 \mathrm{Ma}$ ), while the inferred seawater $\delta^{98} \mathrm{Mo}$ of the early Cambrian Jiumenchong Formation 1.8-2\% $\left(\begin{array}{lll}\sim 520 & \mathrm{Ma}\end{array}\right)$. Compared to the muted $\delta^{98} \mathrm{Mo}$ of Mesoproterozoic, these results confirm an oxygenation event through the EdiacaranCambrian transition, which further prove the idea that global redox change gave an impact on metazoan ecosystems. 